\title{
MONOTONICITY AND INEQUALITIES INVOLVING THE INCOMPLETE GAMMA FUNCTION
}

\author{
Hui-Lin Lv, ZHEN-HANG YANG AND SHENZHOU ZHENG
}

\begin{abstract}
In this paper, by observing the monotonicity of three ratios involving the integral function $\int_{0}^{x} e^{-t^{p}} d t$ for $p, x>0$, we offer some new sharp bounds for the incomplete gamma function, which greatly improve and extend some known results. Also, as by-products, we unexpectedly obtain two power series representations for the incomplete gamma function.
\end{abstract}

Mathematics subject classification (2010): 33B20, 26A48, 26D15.

Keywords and phrases: Incomplete gamma function, monotonicity, inequality.

\section{REFERENCES}

[1] W. F. Xia And Y. M. ChU, Optimal inequalities for the convex combination of error function, J. Math. Inequal., 9(2015), 85-99.

[2] Y. M. ChU, Y. M. LI, W. F. XIA AND X. H. ZhanG, Best possible inequalities for the harmonic mean of error function, J. Inequal. Appl., 2014(2014), Article 529, 9 pages.

[3] Z. H. YANG, W. M. QIAN, Y. M. CHU AND W. ZHANG, On approximating the error function, Math. Inequal. Appl., 21(2)(2018), 469-479.

[4] Y. M. ChU AND T. H. ZhaO, Concavity of the error function with respect to Hölder means, Math. Inequal. Appl. 19(2)(2016), 589595.

[5] Y. M. Li, W. F. XiA, Y. M. ChU AND X. H. Zhang, Optimal lower and upper bounds for the geometric convex combination of the error function, J. Inequal. Appl., 2015(2015), Article 382, 8 pages.

[6] W. GaUTSCHI, Some elementary inequalities relating to the gamma and incomplete gamma function, J. Math. Phys. 38 (1959), no. 1, 77-81.

[7] S. S. GUPTA AND M. N. WAKNIS, A system of inequalities for the incomplete gamma function and the normal integral, Ann. of Math. Stat. 36 (1965), no. 1, 139-149.

[8] A. ElBert AND A. LAFORGIA, An inequality for the product of two integrals related to the incomplete gamma function, J. Inequal. Appl., 5 (2000), 39-51.

[9] J. M. BORWEIN AND O. Y. CHAN, Uniform bounds for the complementary incomplete Gamma function, Math. Inequal. Appl. 12 (2009), no. 1, 115-121.

[10] Y. Komatu, Elementary inequalities for Mills' ratio, PLoS Comput. Biol. 4 (1955), 69-70.

[11] H. O. PollaK, A remark on "An inequality for Mills' ratio" by Y. Komatu, Rep. Statist. Appl. Res. Un. Jap. Sci. Engrs 4 (1956), 110.

[12] A. V. BoyD, Inequalities for Mill's ratio, Rep. Statist. Appl. Res. Un. Jap. Sci. Engrs 6 (1959), 44-46.

[13] D. S. Mitrinović, Analytic Inequalities, Springer-Verlag, 165 (1970), no. 3, 177-181, 291-292 and 385 .

[14] E. Neuman, Inequalities and bounds for the incomplete gamma function, Results Math. 63 (2013), no. 3-4, 1209-1214, DOI: 10.1007/s00025-012-0263-9.

[15] A. Gasull And F. UtZet, Approximating Mills ratio, J. Math. Anal. Appl. 420 (2014), no. 2, 1832 1853, DOI: 10.1016/j.jmaa.2014.05.034.

[16] Z. H. YANG AND Y. M. ChU, On approximating Mills ratio, J. Inequal. Appl. 2015 (2015), no. 1, 273, DOI: 10.1186/s13660-015-0792-3.

[17] F. QI AND Z. HUANG, Inequalities of the complete elliptic integrals, Tamkang J. Math. 29 (1998), no. $3,165-169$. 
[18] F. QI AND S. L. GUO, Inequalities for the incomplete gamma and related functions, Math. Inequal. Appl. 2 (1999), no. 1, 47-53. DOI: 10.7153/mia-02-05.

[19] Z. H. YANG, W. ZHANG AND Y. M. CHU, Monotonicity and inequalities involving the incomplete gamma function, J. Inequal. Appl. 2016 (2016), no. 1, 221, DOI: 10.1186/s13660-016-1160-7.

[20] Z. H. YANG, W. ZHANG AND Y. M. CHU, Monotonicity of the incomplete gamma function with applications, J. Inequal. Appl. 2016 (2016), no. 1, 251, DOI: 10.1186/s13660-016-1197-7.

[21] T. Q. LuO, H. L. Lv, Z. H. YANG AND S. Z. ZHENG, New sharp approximations involving incomplete gamma functions, Results Math. 72 (2017), no. 1-2, 1007-1020, DOI: 10.1007/s00025-0170713-5.

[22] Z. H. YANG, W. ZHANG AND Y. M. CHU, Sharp Gautschi inequality for parameter $0<p<1$ with applications, Math. Inequal. Appl. 20 (2017), no. 4, 1107-1120, DOI: 10.7153/mia-2017-20-71.

[23] M. K. WANG, Y. M. ChU AND S. L. QIU, Asymptotical formulas for Gaussian and generalized hypergeometric functions, Appl. Math. Comput. 276(2016), 44-60.

[24] Y. M. CHU, M. K. WANG AND S. L. QIU, Optimal combination bounds of root-square and arithmetic means for Toader mean, Proc. Indian Acad. Sci. Math. Sci. (1)122(2012), 41-51.

[25] Y. M. ChU AND M. K. WANG, Optimal Lehmer mean bounds for the Toader mean, Results Math. (3-4)61(2012), 223-229.

[26] M. K. WANG, S. L. QIU AND Y. M. CHU, Infinite series formula for Hübner upper bound function with applications to Hersch-Puger distortion function, Math. Inequal. Appl. (3)21(2018), 629-648.

[27] M. K. WANG, Y. M. Li AND Y. M. ChU, Inequalities and infinite product formula for Ramanujan generalized modular equation function, Ramanujan J. (1)46(2018), 189-200.

[28] M. K. WANG AND Y. M. CHU, Landen inequalities for a class of hypergeometric functions with applications, Math. Inequal. Appl. (2)21, 2018, 521-537.

[29] Z. H. YANG, W. M. QIAN, Y. M. CHU AND W. ZHANG, On rational bounds for the gamma function, J. Inequal. Appl. 2017(2017), Article 210, 17 pages.

[30] Z. H. YANG AND Y. M. CHU, A monotonicity property involving the generalized elliptic integral of the first kind, Math. Inequal. Appl. (3)20(2017), 729-735.

[31] W. M. QIAN AND Y. M. CHU, Sharp bounds for a special quasiarithmetic mean in terms of arithmetic and geometric means with two parameters, J. Inequal. Appl. 2017(2017), Article 274, 10 pages.

[32] A. LAFORGIA AND P. NATALINI, Supplements to known monotonicity results and inequalities for the gamma and incomplete gamma functions, J. Inequal. Appl. 2006(2006), Art. ID 48727, 1-8, DOI: $10.1155 / J I A / 2006 / 48727$.

[33] G. D. Anderson, M. Vamanamurthy and M. Vuorinen, Monotonicity rules in calculus, Amer. Math. Monthly 113 (2006), no. 9, 805-816.

[34] M. BieRnACKI AND J. KRZYZ, On the monotonicity of certain functionals in the theory of analytic functions, Ann. Univ. Mariae Curie-Sklodowska, 9 (1955), 135-147.

[35] Z. H. YANG AND J. F. TIAN, Monotonicity and inequalities for the gamma function, J. Inequal. Appl. 2017 (2017), no. 1, 317. Available online at https://doi.org/10.1186/s13660-017-1591-9.

[36] Z. H. YANG, Some properties of the divided difference of psi and polygamma functions, J. Math. Anal. Appl. 455(2017), no. 1, 761-777. Available online at http://dx.doi.org/10.1016/j.jmaa.2017.05.081.

[37] Z. H. YANG, A new way to prove L'Hospital monotone rules with applications, arXiv:1409.6408 [math.CA]. Available online at http://arxiv.org/pdf/1409.6408v1.pdf.

[38] Z. H. YANG, Y. M. ChU, AND M. K. WANG, Monotonicity criterion for the quotient of power series with applications, J. Math. Anal. Appl. 428 (2015), no. 1, 587-604. Available online at http://dx.doi.org/10.1016/j.jmaa.2015.03.043.

[39] Z. H. YANG, W. M. QIAN, Y. M. ChU AND W. ZhANG, On approximating the arithmetic-geometric mean and complete elliptic integral of the first kind, J. Math. Anal. Appl. (2)462(2018), 1714-1726.

[40] F. Belzunce, E. ORTEga AND J. M. Ruiz, On non-monotonic ageing properties from the Laplace transform, with actuarial applications, Insurance Math. Econom. 40 (2007), no. 1, 1-14.

[41] Z. H. YANG, Y. M. CHU AND X. H. ZHANG, Necessary and sufficient conditions for functions involving the psi function to be completely monotonic, J. Inequal. Appl. 2015 (2015), 157, DOI: 10.1186/s13660-015-0674-8.

[42] Z. H. YANG AND Y. M. ChU, Inequalities for certain means in two arguments, J. Inequal. Appl. 2015 (2015), 299, DOI: 10.1186/s13660-015-0828-8. 
[43] Z. H. YAng, Y. M. ChU And X. J, TAO, A double inequality for the trigamma function and its applications, Abstr. Appl. Anal. 2014 (2014), Art. ID 702718, 9 pages. Available online at http://dx.doi.org/10.1155/2014/702718.

[44] Z. H. YANG AND J. F. TIAN, Monotonicity and sharp inequalities related to gamma function, J. Math. Inequal. 12 (2018), no. 1, 1-22, DOI: 10.7153/jmi-2018-12-01.

[45] M. Abramowitz, I. A. Stegun And D. Miller, Handbook of Mathematical Functions With Formulas, Graphs and Mathematical Tables (National Bureau of Standards Applied Mathematics Series No. 55), J. Appl. Mech. 32 (1965), no. 1, 239, DOI: 10.1115/1.3625776. 